\title{
Neuromodulators Enhance Transmitter Release by Two Separate Mechanisms at the Inhibitor of Crayfish Opener Muscle
}

\author{
Andrey Vyshedskiy, ${ }^{1}$ Kerry R. Delaney, ${ }^{2}$ and Jen-Wei Lin ${ }^{1}$ \\ ${ }^{1}$ Department of Biology, Boston University, Boston, Massachusetts 02215, and 2Department of Biological Sciences, \\ Simon Fraser University, Burnaby, British Columbia, V5A 156 Canada
}

\begin{abstract}
A presynaptic voltage control method has been used to investigate the modulatory effects of serotonin $(5-\mathrm{HT})$ and okadaic acid (OA) on the inhibitory junction of the crayfish opener muscle. Instead of using action potentials, we used $20 \mathrm{msec}$ pulses depolarized to $0 \mathrm{mV}$ to activate transmitter release. This approach allowed us to monitor two separate physiological parameters related to the release process. The first parameter, transmitter release kinetics, is characterized as the delay when inhibitory postsynaptic conductance reaches its half-maximum $\left(I S_{50}\right)$. The second parameter, the total area of IPSG (IPS$\mathrm{G}_{\text {area }}$ ), estimates total transmitter output. We have reported previously that the F2 component of synaptic facilitation is associated with a decrease in IPSG ${ }_{50}$ but without a change in $I P S G_{\text {area. }}$. These results raised the possibility that IPSG ${ }_{50}$ and $I_{P S G}$ area could be mediated by separate mechanisms that were modulated independently. To explore this possibility, we investigated the effects of 5-HT (100-200 nm) and OA (2.5 $\mu \mathrm{m})$ on the
\end{abstract}

The strength of synaptic transmission can be regulated by either activity-dependent or modulator-mediated processes. Activitydependent synaptic enhancement includes both short- and longterm synaptic enhancement. Four distinct components of shortterm synaptic enhancement have been identified, F1 and F2 components of facilitation, augmentation, and post-tetanic potentiation (Magleby, 1987). Although it generally is agreed that an increase in intracellular free $\mathrm{Ca}$ concentration $\left(\left[\mathrm{Ca}^{2+}\right]_{\mathrm{i}}\right)$ is the main driving element for short-term synaptic enhancement, specific molecular processes that are activated by an increase in $\left[\mathrm{Ca}^{2+}\right]_{\mathrm{i}}$ have not yet been identified (Zucker, 1996). Modulatormediated processes represent a more diverse collection of processes. Modulators have been shown to increase transmitter release by regulating presynaptic calcium influx (McGehee et al., 1995; Byrne and Kandel, 1996; Dittman and Regehr, 1996; Huang et al., 1996) or by directly modulating the release machinery (Atwood et al., 1989; Man-Son-Hing et al., 1989; Dale and Kandel, 1990; Malgaroli and Tsien, 1992; Scanziani et al., 1992; Scholz and Miller, 1992; Klein, 1994; Dittman and Regehr, 1996; Trudeau et al., 1996). The fact that there are so many examples showing direct modulation of the release machinery suggests that more than one process may be involved in this type of presynaptic mechanism. The separation and isolation of individual mecha-

\footnotetext{
Received Jan. 14, 1998; revised April 24, 1998; accepted April 28, 1998.

This work was supported by National Institutes of Health Grant NS31707 (to J.W.L.) and by the Natural Sciences and Engineering Research Council Canada (OG 0121698 to K.D.). We thank Nicky Schweitzer for correcting our English.

Correspondence should be addressed to Dr. Jen-Wei Lin, Department of Biology, Boston University, 5 Cummington Street, Boston, MA 02215.

Copyright (C) 1998 Society for Neuroscience $\quad 0270-6474 / 98 / 185160-10 \$ 05.00 / 0$
}

two parameters. 5-HT and OA enhanced IPSG neither by changing the sensitivity of postsynaptic receptors, as tested by iontophoretically ejected GABA, nor by elevating resting and action potential-activated presynaptic free calcium, as monitored by fura-2 imaging. 5-HT and OA decreased IPSG ${ }_{50}$ by $3.0 \pm 1.4$ and $3.6 \pm 1.1 \mathrm{msec}$, respectively, and increased $\mathrm{IPSG}_{\text {area }}$ by $50 \pm 21$ and $37 \pm 6 \%$, respectively. The ability of F2 facilitation to accelerate release kinetics was reduced in the presence of the modulators, suggesting that the mechanism underlying the accelerated release kinetics was shared by the two modes of synaptic enhancement. This report demonstrates that the acceleration in release kinetics and the increase in total release are two separate mechanisms for enhancing transmitter output and that these two mechanisms can be activated without changes in presynaptic calcium dynamics.

Key words: IPSG; GABA; synaptic transmission; modulators; transmitter release; serotonin; okadaic acid

nisms at the physiological level are urgently needed for further investigation of their molecular counterparts.

The excitatory junction of the crayfish claw opener has been used as a model system to study both activity-dependent and modulator-mediated synaptic plasticity. It has been demonstrated that this junction exhibits both short- and long-term activitydependent plasticity (Bittner, 1989; Dixon and Atwood, 1989a). The crayfish excitor also has been used for in-depth investigation of modulator-mediated synaptic enhancement (Fischer and Florey, 1983; Dixon and Atwood, 1985; Swain et al., 1991). Specific second messenger pathways underlying the effects of serotonin have been identified (Dixon and Atwood, 1989b,c). Furthermore, it has been shown that serotonin increases transmitter output without increasing presynaptic calcium influx or the resting calcium level (Delaney et al., 1991). Therefore, there appear to be both calcium-driven and calcium-independent processes that can enhance transmitter output. To dissect the various presynaptic mechanisms, one usually relies on binomial analysis (Zucker, 1973; Mclachlan, 1978), pharmacological manipulations that reveal presynaptic release probability (Hessler et al., 1993; Rosenmund et al., 1993), or the use of controlled presynaptic pulses (Hochner et al., 1986a,b; Klein, 1994). This last approach simplifies the analysis of presynaptic plasticity by controlling for the class of mechanism mediated by potassium channel modulation. We have implemented a presynaptic voltage control method (Vyshedskiy and Lin, 1997a) at the inhibitory junction of the crayfish neuromuscular synapse. Using $20 \mathrm{msec}$ presynaptic steps as test pulses, we have revealed that the F2 component of synaptic facilitation was associated with an acceleration in transmitter 
release kinetics (Vyshedskiy and Lin, 1997c). [F1 and F2 components of synaptic facilitation at the crayfish inhibitor are characterized by their decay time constants of 19 and $520 \mathrm{msec}$, respectively (Vyshedskiy and Lin, 1997b)]. In addition, the total amount of transmitter release (total release) was not changed during F2 facilitation. If one assumes that release kinetics and total release represent two separate mechanisms, the facilitation process would be presumed to use only one of them. To explore this possibility further, we believed it was essential to show that both parameters could be modulated. In this report we show that 5-HT and $\mathrm{OA}$ enhance transmitter release at the inhibitor not by modulating calcium influx but by simultaneously accelerating transmitter release kinetics and increasing the total amount of transmitter release.

\section{MATERIALS AND METHODS}

Animals and preparations. Crayfish, Procambarus clarkii, were obtained from Carolina Biological (Burlington, NC). Animals were maintained at $23^{\circ} \mathrm{C}$ until use. Experiments using the voltage control method as well as ratiometric calcium measurements were performed at $15^{\circ} \mathrm{C}$ (Vyshedskiy and Lin, 1997a). Experiments performed at room temperature $\left(23^{\circ} \mathrm{C}\right)$ are specified in the figure legends. The typical size of the animals was $\sim 3.8 \mathrm{~cm}$, head to tail. The opener muscle of the first walking leg was used for all experiments. Details of the experimental setup have been described before (Vyshedskiy and Lin, 1997a). Briefly, a presynaptic voltage electrode penetrated a secondary axon near a branch point where a tertiary branch emerged. A presynaptic current electrode penetrated the main branch point of the inhibitor. The distance between the two presynaptic electrodes was between 100 and $150 \mu \mathrm{m}$. A two-electrode voltage clamp amplifier (GeneClamp 500, Axon Instruments, Foster City, CA) was used to control presynaptic potential. Two postsynaptic electrodes penetrated a muscle fiber near the presynaptic voltage electrode. One electrode was used to inject current, and the second electrode recorded membrane potential. This arrangement allowed us to monitor chloride equilibrium potential $\left(E_{\mathrm{Cl}}\right)$, input resistance $\left(R_{\mathrm{m}}\right)$, and the time constant $\left(\tau_{\mathrm{m}}\right)$ of the muscle fiber under study.

Experiments involving action potentials were conducted in a control saline (in mM): $195 \mathrm{NaCl}, 5.4 \mathrm{KCl}, 13.5 \mathrm{CaCl}_{2}, 2.6 \mathrm{MgCl}_{2}$, and 10 sodium Na-HEPES, $\mathrm{pH}$ 7.4. In voltage control experiments the control saline was replaced by experimental solution (in $\mathrm{mM}$ ): $155 \mathrm{NaCl}, 40$ tetraethylammonium (TEA) chloride, $5.4 \mathrm{KCl}, 10 \mathrm{CaCl}_{2}, 6.1 \mathrm{MgCl}_{2}, 10$ Na-HEPES, and 14 -aminopyridine plus $300 \mathrm{~nm}$ tetrodotoxin, $\mathrm{pH}$ 7.4. All chemicals were purchased from Sigma (St. Louis, MO), except OA, which was ordered from Research Biochemicals (Natick, MA). Morphological examination of the terminal branches that innervated the recorded muscle fiber was performed after each experiment, by sketching or photography (Vyshedskiy and Lin, 1997a).

Modulator applications. The concentration of 5-HT used in all experiments was 100-200 nM. Previous studies of excitatory junctions have used higher concentrations, from 1 to $\sim 10 \mu \mathrm{M}$ (Dixon and Atwood, 1985). This was not practical for us because the infusion of high-level 5 -HT induced muscle contraction in the presence of $\mathrm{K}^{+}$channel blockers. The introduction of 5-HT was achieved by increasing the perfusion rate for 3-5 min to allow an exchange of five recording chamber volumes, $\sim 20 \mathrm{ml}$. Then the perfusion rate was returned to the control level. This procedure created a transient increase in temperature, which returned to its control value within $5 \mathrm{~min}$ after the perfusion rate was reduced to control level, $1 \mathrm{ml} / \mathrm{min}$.

The effects of okadaic acid were studied in the absence of perfusion. Stock solution, $300 \mu \mathrm{l}$ of $30 \mu \mathrm{M} \mathrm{OA}$ (okadaic acid ammonium) in experimental solution, was added to the recording chamber, $\sim 3.6 \mathrm{ml}$, to yield a final concentration of $2.5 \mu \mathrm{M}$. Control data were collected for 40 min, in the absence of perfusion, before OA application. Stopping the perfusion did not affect transmitter release for as long as $2 \mathrm{hr}$ (see Fig. $1 B_{2}$, for example).

Iontophoretic application of GABA. The effects of 5-HT and OA on postsynaptic GABA receptors were investigated by iontophoretically applied GABA. The GABA-delivering pipette had a resistance of 30 $\mathrm{M} \Omega$, with $1 \mathrm{M}$ GABA titrated to $\mathrm{pH} 4$ with $\mathrm{HCl}$. GABA was delivered iontophoretically by current pulses of $\sim 1 \mu \mathrm{A}$ and 5-20 msec. Long-term stability of GABA ejection was best achieved by using (1) sharp GABA electrodes with a short shank and (2) a retention current of $5 \mathrm{nA}$ to decrease the leakage of GABA. The placement of the GABA pipette, however, depended on experimental conditions. In the study of OA the GABA-containing pipette was placed as close to a "hot spot" on the muscle fiber as possible. The pipette touched the muscle fiber, and the extent to which GABA was diluted at the pipette tip appeared to be minimal.

With the GABA pipette positioned on a hot spot, application of 5-HT invariably led to a decrease in amplitude, and an increase in rise time, of the GABA-evoked response. These changes, with the concurrent instability of muscle membrane potential, suggest that the introduction of 5 -HT triggered a small muscle contraction $(n=8)$. It has been shown that a small displacement, in the range of $5 \mu \mathrm{m}$, between the GABA pipette and a "hot spot" may lead to a 50\% decrease in GABA-evoked responses (Takeuchi and Takeuchi, 1965). To minimize the impact of small movements on the GABA-activated potential change, we positioned the GABA-containing electrode at some distance from the muscle surface, $\sim 10 \mu \mathrm{m}$. In this configuration the GABA-evoked response slowly decreased over time (see Fig. $2 A_{1}$ ), presumably because of the continuous dilution of the GABA solution at the tip of electrode. The statistical analysis of experiments involving 5-HT application was performed after the slow decline was corrected for by linear extrapolation.

Presynaptic calcium imaging. Calcium concentration in presynaptic terminals was measured as previously described (Delaney et al., 1989). An Olympus Quartz $60 \times, 0.8$ numerical aperture water immersion objective and a cooled CCD camera (Photometrics $\mathrm{CH} 250$ ) were used to image the fluorescence from individual terminals. Presynaptic axons were filled with fura- 2 by iontophoresis to a concentration of $<200 \mu \mathrm{M}$. Selective stimulation of the inhibitor axon at a frequency of $8-10 \mathrm{~Hz}$ for $30 \mathrm{sec}$ was used to elevate $\left[\mathrm{Ca}^{2+}\right]_{\mathrm{i}}$ to a plateau level to assess the effect of 5-HT or OA on action potential-mediated calcium influx. The change in $\left[\mathrm{Ca}^{2+}\right]_{\mathrm{i}}$ was calculated as the difference between pretetanus $\left[\mathrm{Ca}^{2+}\right]_{\mathrm{i}}$ and the $\left[\mathrm{Ca}^{2+}\right]_{\mathrm{i}}$ at the end of each tetanus after $\left[\mathrm{Ca}^{2+}\right]_{\mathrm{i}}$ reached a plateau (Tank et al., 1995). The change in $\left[\mathrm{Ca}^{2+}\right]_{\mathrm{i}}$ during exposure to 5-HT or OA, 30-45 min after the modulators were applied, was compared with the average of three control trains delivered before the application of modulators. To ensure that the modulators were accessing the terminals and having an effect on synaptic transmission, we monitored in several experiments the IPSPs from proximal muscle fibers simultaneously with calcium-imaging measurements. The modulators were always effective when we checked the enhancement of transmitter release in calcium-imaging experiments.

Data analysis. The application of the voltage control method is valid only if the space constant of the inhibitor is not affected by 5-HT and OA. It was shown previously that the quality of spatial control correlates well with the shape of the depolarization-release (D-R) coupling plot of IPSPs activated by $5 \mathrm{msec}$ presynaptic pulses (Vyshedskiy and Lin, 1997a). In a spatially well controlled terminal, suppression of the IPSP can be achieved when the presynaptic terminal is depolarized beyond 0 $\mathrm{mV}$. To examine the possible effects of 5-HT and OA on the presynaptic space constant, we compared the maximal point of the $\mathrm{D}-\mathrm{R}$ coupling plot before and after the modulators were applied. The maximal point occurred at $-5.0 \pm 5.0$ and at $-1.0 \pm 1.4 \mathrm{mV}$, respectively, before and after 5-HT application $(n=4)$. The control and experimental maximal points in OA experiments were $4.4 \pm 6.5$ and $6.4 \pm 5.7 \mathrm{mV}(n=5)$, respectively. The small differences in the maximal points were not statistically significant. In addition, the modulators did not alter the shape of the D-R coupling curves, further suggesting that the presynaptic space clamp characteristics remained unchanged.

The use of chloride-containing electrodes in postsynaptic recordings increased the intramuscular chloride concentration, which resulted in depolarizing IPSP. Signal-to-noise ratio considerations prohibited us from performing simultaneous pre- and postsynaptic voltage clamp. To take into account the nonlinear summation of IPSP, we routinely used the two postsynaptic electrodes to measure $E_{\mathrm{C} 1}, R_{\mathrm{m}}$, and $\tau_{\mathrm{m}}$ of the muscle fiber under investigation. The chloride driving force $\left(\Delta E_{\mathrm{Cl}}\right)$, which is defined as the difference between resting membrane potential and $E_{\mathrm{Cl}}$, and the values of $R_{\mathrm{m}}$ and $\tau_{\mathrm{m}}$ allowed us to reconstruct inhibitory postsynaptic conductance (IPSG) from IPSP (Vyshedskiy and Lin, 1997a). The validity of this conversion has been verified previously by comparing the time course of an IPSC calculated from IPSG with that of an IPSC measured with the use of two-electrode voltage clamp. $\Delta E_{\mathrm{Cl}}, R_{\mathrm{m}}$, and $\tau_{\mathrm{m}}$ of individual experiments are listed in the figure legends. All of the statistical data shown in this report are presented in the form of mean \pm $\mathrm{SD}$, with sample size $(n)$ that represents the number of preparations. Student's $t$ test was used in all statistical analyses. 
Figure 1. 5-HT and OA enhance action potential-mediated transmitter release of the inhibitor. $A$, Time courses of peak IPSGs enhanced by $100 \mathrm{~nm} 5$-HT $\left(A_{l}\right)$ and $2.5 \mu \mathrm{M}$ OA $\left(A_{2}\right)$. Peak IPSGs were normalized to the average IPSG measured 5 min before the modulators were applied. Insets in $A_{1}$ and $A_{2}$, Control (1 and dashed line) and enhanced (2 and solid line) IPSPs that represent the averages of 60 and 75 trials, respectively. $\Delta E_{\mathrm{Cl}}$ and $R_{\mathrm{m}}$ measured before and after 5-HT was applied were $9 \mathrm{mV}, 0.45 \mathrm{M} \Omega$ and $8.3 \mathrm{mV}, 0.4 \mathrm{M} \Omega$, respectively. $\Delta E_{\mathrm{Cl}}$ and $R_{\mathrm{m}}$ measured before and after $\mathrm{OA}$ was applied were $10 \mathrm{mV}, 0.6 \mathrm{M} \Omega$ and 10 $\mathrm{mV}, 0.7 \mathrm{M} \Omega$, respectively. $B$, Averaged time courses showing the effects of 5-HT $(n=12)$ and OA $(n=5)$ on IPSG amplitude. Open triangles in $B_{2}$ represent averaged results $(n=5)$ from control experiments in which perfusion was stopped but in which no OA was added. All experiments were performed at $23^{\circ} \mathrm{C}$.
5-HT

$A_{1}$

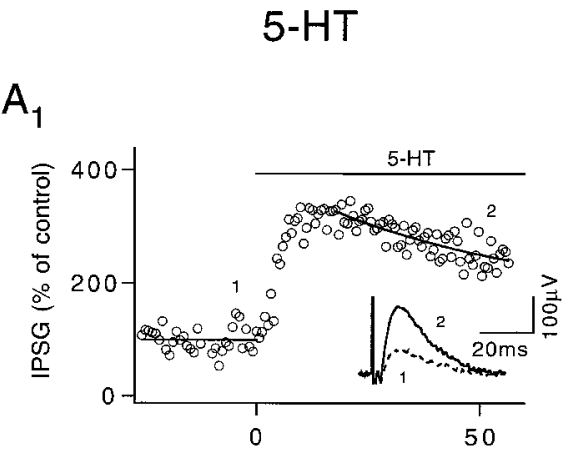

$\mathrm{B}_{1}$

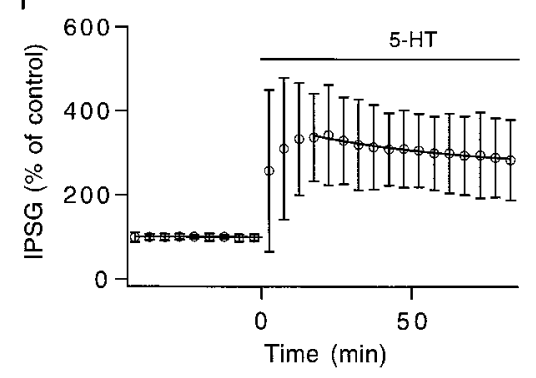

$\mathrm{OA}$
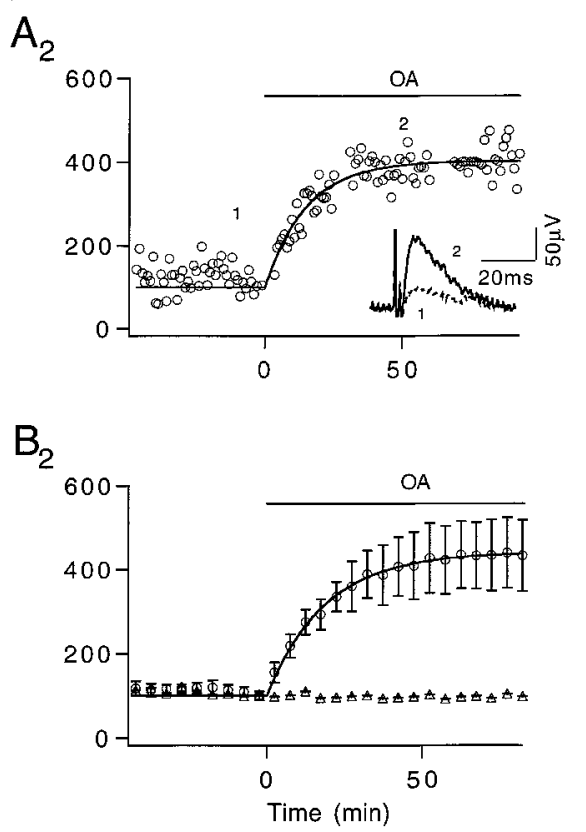

\section{RESULTS}

\section{5-HT and OA enhance inhibitory synapses of the crayfish opener muscle}

In the absence of previously published data, we first investigated the effects of 5-HT and OA on the crayfish inhibitor. Action potential-activated IPSPs were compared before and after the modulators were introduced. To control for factors that may affect IPSP amplitude, such as drifting $E_{\mathrm{C} 1}$ or nonlinear summation of IPSP amplitudes, we converted IPSP peak amplitudes to IPSG for quantitative analysis. Figure $1 A_{1}$ shows that $100 \mathrm{~nm}$ 5-HT initially increases IPSG amplitude to $340 \%$ of control level. The enhancement then slowly decays to $250 \%$. The inset shows averaged IPSPs obtained in control saline (dashed line) and at 40-60 min after 5-HT application (solid line). The time course of IPSG enhancement averaged from 12 preparations is shown in Figure $1 B_{1}$. There was a large variation in the magnitude of initial enhancement. The maximal level, measured within $20 \mathrm{~min}$ of 5-HT application, ranged from 210 to $892 \%$. The enhancement then settled into a phase of slow decline for the next hour. Data collected between 40 and 60 min after 5-HT application were considered to be in a steady state. The average value of the steady-state enhancement was $304 \pm 88 \%$.

Figure $1 \mathrm{~A}_{2}$ shows that $2.5 \mu \mathrm{M}$ OA induced an increase in IPSG that rose gradually and reached a plateau. The inset shows averaged IPSP recorded in control saline (dashed line) and at 40-60 min after OA application (solid line). The time course and amplitude of transmitter release enhancement mediated by OA were very similar to those observed at the crayfish excitor (Swain et al., 1991). Averaged results from five preparations are shown in Figure $1 B_{2}(O)$, in which the steady-state level of OA-induced enhancement was $412 \pm 65 \%$ of control level. The strength of synaptic transmission remained unchanged in control experiments $(\Delta)$ in which perfusion was stopped but no OA was introduced $(n=5)$. The enhancement of transmitter release mediated by both modulators remained stable throughout the period of investigation. In the remaining part of this report we focus on the effects of 5-HT and OA during the steady state.

5-HT and OA-mediated synaptic enhancement is not attributable to an increase in GABA receptor sensitivity

Although previous studies have established that 5-HT and OA enhance transmitter release by presynaptic mechanisms at the excitor (Fischer and Florey, 1983; Swain et al., 1991), no such evidence is available for the inhibitor. Because of the small driving force for IPSPs, it is not possible to evaluate the postsynaptic effects of these modulators by miniature IPSPs. We therefore examined this issue by investigating the GABA-mediated conductance change ( $\left.g_{\mathrm{GABA}}\right)$ activated by iontophoretically applied GABA. Figure 2, $A_{1}$ and $A_{2}$, shows that neither 5-HT nor OA affected GABA-activated conductance, although action potential-activated IPSGs were enhanced by the modulators (Fig. $\left.2 B_{1}, B_{2}\right)$. Traces in the insets illustrate the membrane potential changes activated by iontophoretically applied GABA before (dashed line) and after (solid line) the modulators were applied. These experiments were repeated in five preparations for each modulator in which $g_{\mathrm{GABA}}$ measured $1 \mathrm{hr}$ after applying 5-HT and OA was $95 \pm 5$ and $95 \pm 9 \%$ of control levels, respectively. (The statistical analysis of the 5-HT effect was performed after the declining trend had been corrected for by linear extrapolation; see Materials and Methods).

\section{5-HT and OA-mediated synaptic enhancement is not attributed to increased presynaptic calcium influx}

To understand the mechanisms underlying 5-HT and OAactivated synaptic enhancement in the inhibitor, we examined the effects of these modulators on resting and action potentialactivated $\left[\mathrm{Ca}^{2+}\right]_{\mathrm{i}}$. A previous study has demonstrated that 5-HT does not enhance transmitter output by increasing $\left[\mathrm{Ca}^{2+}\right]_{\mathrm{i}}$ in the excitor (Delaney et al., 1991). Experiments performed in the inhibitor are shown here. The example shown in Figure $3 A_{1}$ indicates that the level of resting and action potential-activated 
5-HT

$\mathrm{A}_{1}$

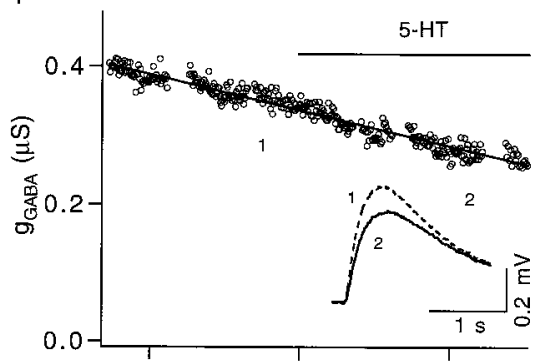

$\mathrm{B}_{1}$

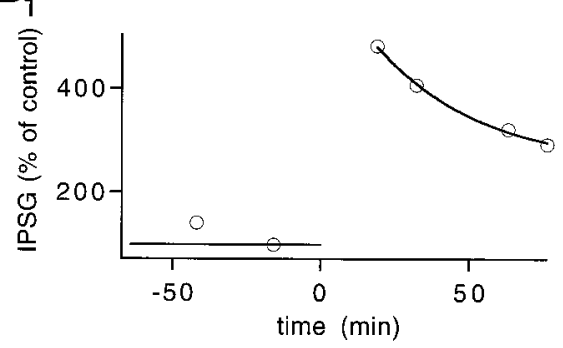

A

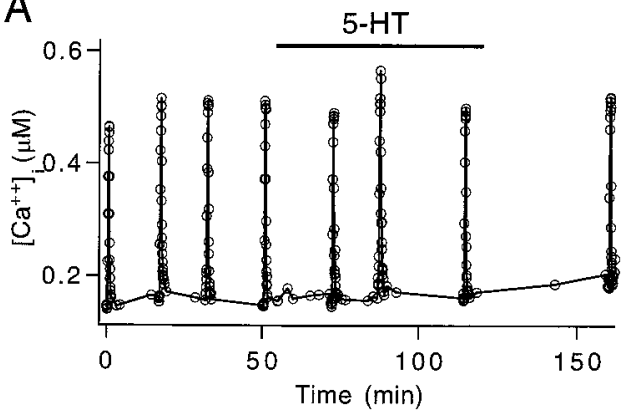

$\mathrm{A}_{2}$

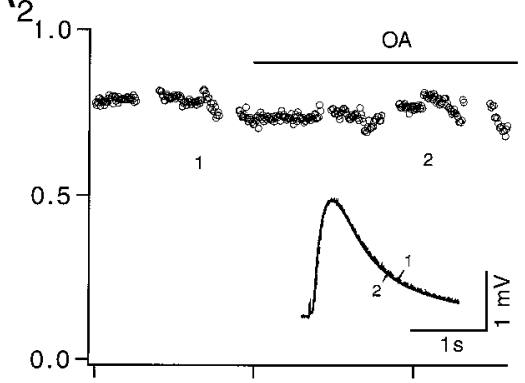

$\mathrm{B}_{2}$

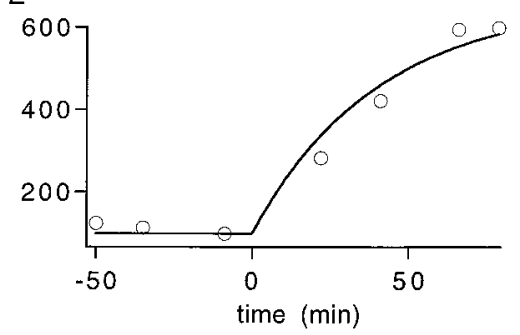

Figure 2. 5-HT and OA have no effect on GABA receptors of muscle fibers. $A, 5-\mathrm{HT}\left(A_{1}\right)$ and OA $\left(A_{2}\right)$ do not change $g_{\mathrm{GABA}} \cdot g_{\mathrm{GABA}}$ amplitudes were calculated from membrane potential changes in a muscle fiber activated by iontophoretically applied GABA. Insets, GABA-activated membrane potential changes before ( 1 and dashed line) and after ( 2 and solid line) modulator application. The traces represent the averages of 38 trials. $B$, IPSGs calculated from action potential-activated IPSPs in the same muscle fibers. Both 5-HT $\left(B_{1}\right)$ and OA $\left(B_{2}\right)$ increase the IPSG amplitude. $\Delta E_{\mathrm{Cl}}$ and $R_{\mathrm{m}}$ measured before and after 5-HT application were $7.5 \mathrm{mV}, 0.21 \mathrm{M} \Omega$ and $7.5 \mathrm{mV}, 0.21$ $\mathrm{M} \Omega$, respectively. The same parameters measured before and after OA application were 8.8 $\mathrm{mV}, 0.29 \mathrm{M} \Omega$ and $9 \mathrm{mV}, 0.3 \mathrm{M} \Omega$, respectively. All experiments were performed at $23^{\circ} \mathrm{C}$.
B

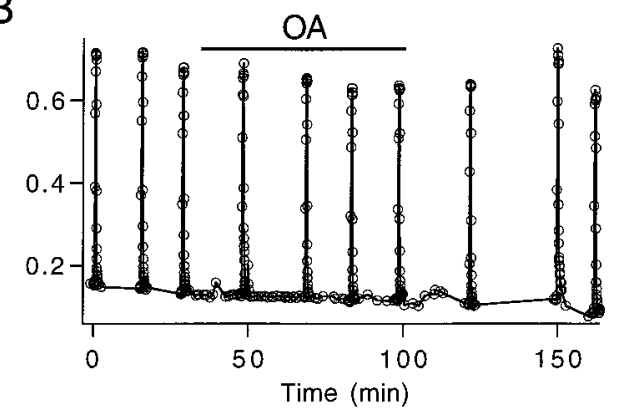

Figure 3. Effects of 5-HT and OA on $\left[\mathrm{Ca}^{2+}\right]_{\mathrm{i}}$ level. Resting $\left[\mathrm{Ca}^{2+}\right]_{\mathrm{i}}$ levels are not changed by 5 -HT $(A)$ or OA $(B)$. Activity-dependent calcium influx was activated by a train of $10 \mathrm{~Hz}$ action potentials for $30 \mathrm{sec}$. 5 -HT ( $200 \mathrm{~nm})$ did not create any detectable change in the $\left[\mathrm{Ca}^{2+}\right]_{\mathrm{i}}$ increase activated by the action potential train $(A)$. OA $(2.5 \mu \mathrm{M})$ application caused a small but significant decrease in the $\left[\mathrm{Ca}^{2+}\right]_{\mathrm{i}}$ increase activated by the same stimulation as in $A(B)$.
$\left[\mathrm{Ca}^{2+}\right]_{\mathrm{i}}$ was not increased by $200 \mathrm{~nm} 5$-HT. In three preparations the resting $\left[\mathrm{Ca}^{2+}\right]_{\mathrm{i}}$ level changed $<50 \mathrm{~nm}$ during the first $30 \mathrm{~min}$ after 5-HT addition. Small changes like these cannot be resolved confidently by fura-2 imaging over the time scale studied here (Delaney et al., 1989; Tank et al., 1995). Although exposure to 1-2 $\mu \mathrm{M} 5$-HT has been reported to reduce slightly the accumulation of $\left[\mathrm{Ca}^{2+}\right]_{\mathrm{i}}$ during repetitive stimulation in the excitor (Delaney et al., 1991), application of $200 \mathrm{~nm}$ 5-HT to the inhibitor, in three preparations, changed the action potential-activated $\left[\mathrm{Ca}^{2+}\right]_{\mathrm{i}}$ increase by $2.1 \pm 3.9 \%$, which is not statistically different from zero. The resting level of $\left[\mathrm{Ca}^{2+}\right]_{\mathrm{i}}$ also was not affected consistently by $2.5 \mu \mathrm{M}$ OA, whereas action potential-activated $\left[\mathrm{Ca}^{2+}\right]_{\mathrm{i}}$ was decreased slightly. Figure $3 B$ is an example of a typical experiment in which a slight downward shift in resting $\left[\mathrm{Ca}^{2+}\right]_{\mathrm{i}}$ was seen before the addition of OA, and this trend was not affected by the addition or washout of OA. In six preparations a small but significant decrease, $10.7 \pm 5.6 \%$, in the accumulation of $\left[\mathrm{Ca}^{2+}\right]_{\mathrm{i}}$ during trains of action potentials was observed between 30 and 60 min after the addition of OA. The small decrease in action potential-elevated $\left[\mathrm{Ca}^{2+}\right]_{\mathrm{i}}$ can be attributed to a slight narrowing of presynaptic action potential duration (data not shown; see also Swain et al., 1991). Therefore, 5-HT and OA do not mediate synaptic enhancement by increasing presynaptic calcium influx.

\section{5-HT and OA enhance synaptic transmission by accelerating release kinetics and increasing the total release}

Because 5-HT and OA enhance synaptic transmission without altering the sensitivity of postsynaptic GABA receptors or increasing presynaptic calcium influx, it was possible that these modulators enhanced transmitter output by regulating the release machinery directly. To investigate this possibility, we used the voltage control method to examine the effects of these modulators on the kinetics of transmitter release and total release mediated by $20 \mathrm{msec}$ presynaptic steps. Figure $4, A_{1}$ and $A_{2}$, shows examples of pre- (lower traces) and postsynaptic (upper traces) recordings obtained before (dashed line) and after (solid line) the modulators were applied. The waveforms of presynaptic voltage steps were not altered by the modulators. However, transmitter release was enhanced, as indicated by the larger IPSP amplitudes. In a total of 14 experiments, seven for 5-HT and seven for OA, the shapes of presynaptic voltage steps recorded before and after applying the modulators were superimposable.

To analyze transmitter release quantitatively, we converted IPSPs into IPSG (Vyshedskiy and Lin, 1997a,c). Figure 4, $B_{1}$ and $B_{2}$, illustrates IPSGs converted from IPSPs shown in Figure 4, $A_{1}$ and $A_{2}$. Transmitter release kinetics was characterized as the time when IPSG reaches half-maximum $\left(\mathrm{IPSG}_{50}\right)\left(\right.$ Fig. $\left.4 B_{1}, \bigcirc\right)$. Both 


\section{5-HT}
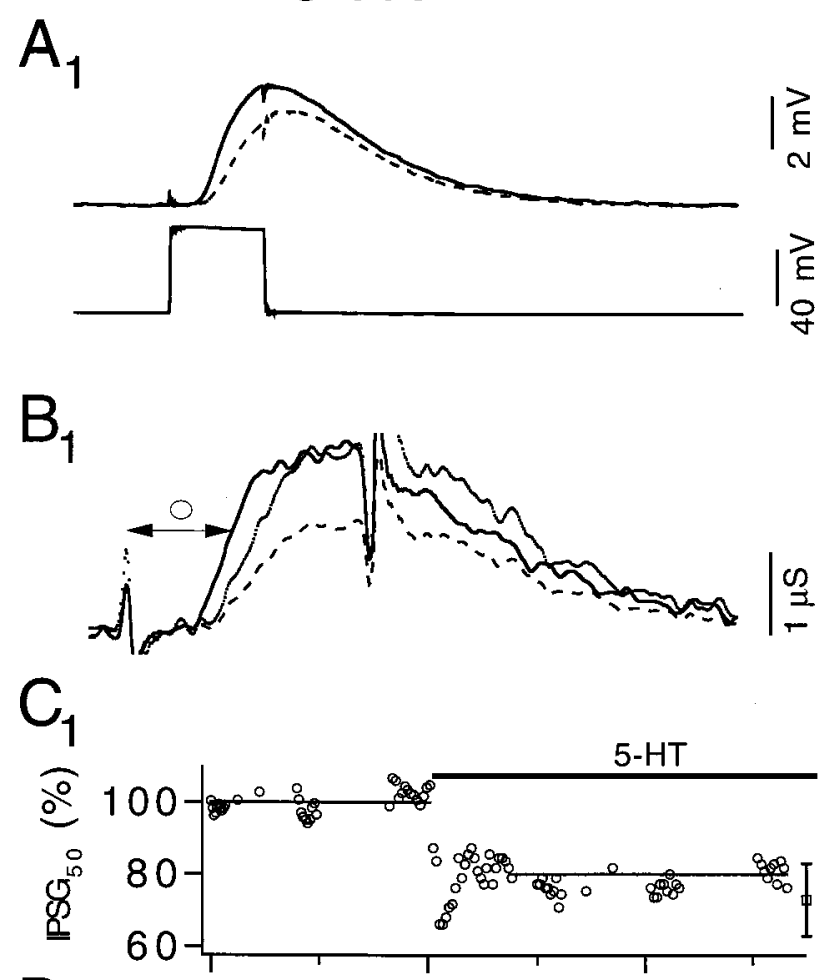

$\mathrm{D}_{1}$

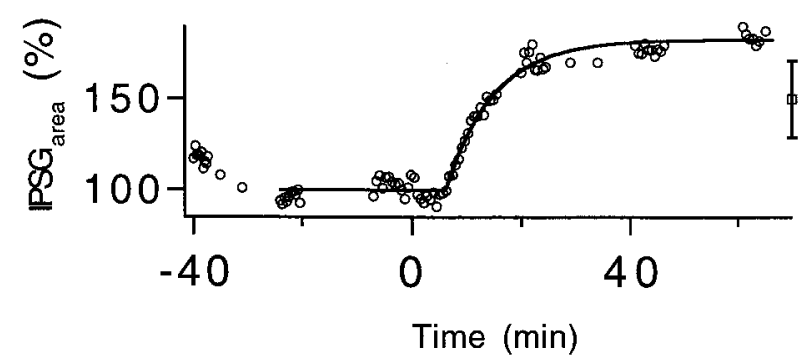

$\mathrm{OA}$

$\mathrm{A}_{2}$
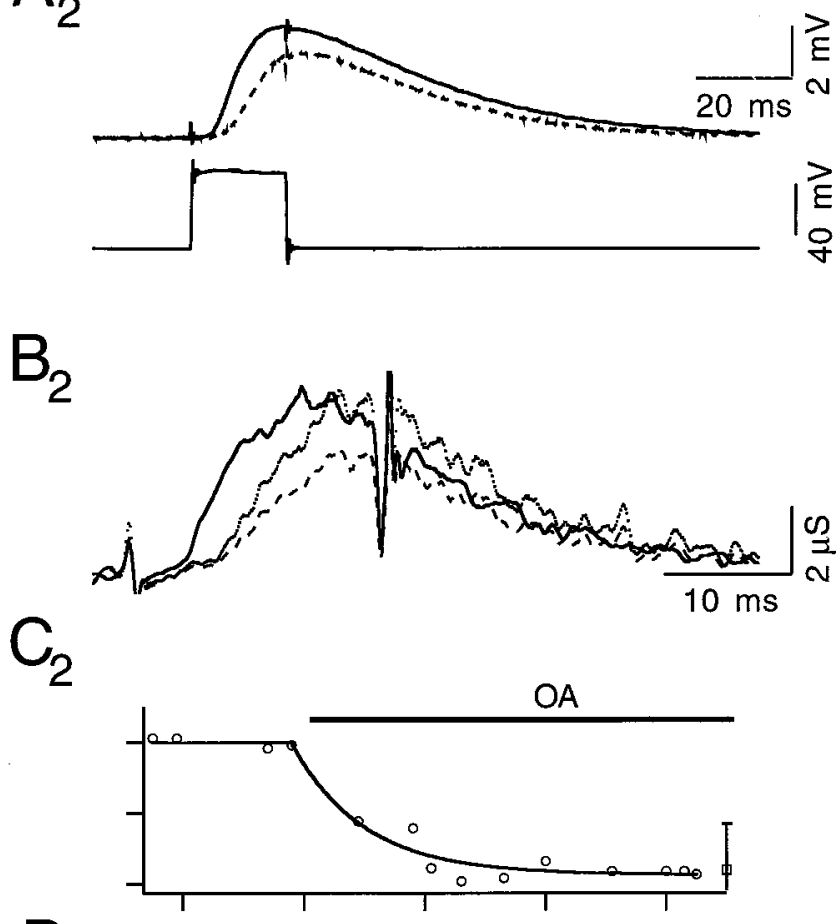

$\mathrm{D}_{2}$

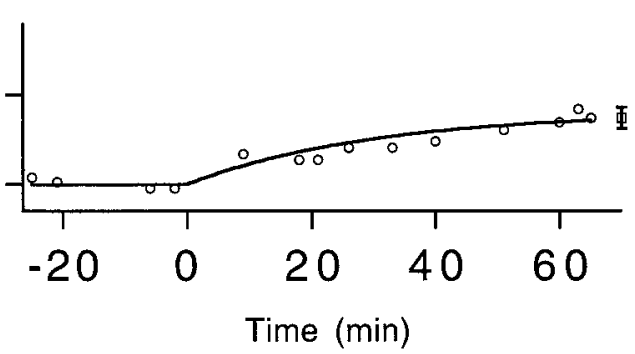

Figure 4. 5-HT and OA accelerate release kinetics and increase $\mathrm{IPSG}_{\text {area }} \cdot A$, Pre- (lower) and postsynaptic (upper) potentials recorded 5 min before (dashed line) and $\sim 50 \mathrm{~min}$ after (solid line) $100 \mathrm{~nm} 5-\mathrm{HT}\left(A_{1}\right)$ and $2.5 \mu \mathrm{M}$ OA $\left(A_{2}\right)$ were applied. Presynaptic steps were $20 \mathrm{msec}$ in duration and depolarized to $0 \mathrm{mV} . A_{1}$ and $A_{2}$ share the same time scale. $B$, IPSGs converted from IPSPs shown in $A$. 5-HT $\left(B_{1}\right)$ and OA $\left(B_{2}\right)$ increase IPSG area significantly. The kinetics of IPSG is quantified by measuring the interval between the beginning of the pulse and the half-maximum point of IPSG (O). $B_{1}$ and $B_{2}$ share the same time scale. $C$, Changes of IPSG $_{50}$ over time after 5-HT $\left(C_{1}\right)$ and OA $\left(C_{2}\right)$ application. $Y$-scales are identical on both graphs. Averaged results, with SD, are shown at the end (see Results). $D$, Time course of change in $\mathrm{IPSG}_{\text {area }}$ in response to 5-HT $\left(D_{1}\right)$ and OA $\left(D_{2}\right)$ application. $Y$-scales are identical on both graphs. Averaged results, with SD, are shown at the end (see Results). $\Delta E_{\mathrm{Cl}}, R_{\mathrm{m}}$, and $\tau_{\mathrm{m}}$ of the muscle fiber measured before and after 5-HT application were $10.1 \mathrm{mV}, 0.47 \mathrm{M} \Omega, 9.2 \mathrm{msec}$ and $10.3 \mathrm{mV}, 0.47 \mathrm{M} \Omega, 8.9 \mathrm{msec}$, respectively. The membrane characteristics of the muscle fiber used in the OA experiment were $5.6 \mathrm{mV}, 0.66 \mathrm{M} \Omega, 13.8 \mathrm{msec}$ and $6.2 \mathrm{mV}, 0.75 \mathrm{M} \Omega, 17.0 \mathrm{msec}$, respectively.

5-HT and OA decreased IPSG $_{50}$. This effect is best visualized by scaling control IPSG to the height of enhanced IPSG (Fig. $4 B_{1}, B_{2}$, dotted line). The effect of the modulators on IPSG $_{50}$ over time are plotted in Figure $4, C_{1}$ and $C_{2}$, where IPSG $_{50}$ was reduced by $22 \%$ (2.2 $\mathrm{msec})$ in $100 \mathrm{~nm} 5-\mathrm{HT}$ and by $37 \%$ ( $3.9 \mathrm{msec})$ in $2.5 \mu \mathrm{M}$ OA. On average, 5-HT accelerated the release kinetics by $27 \pm 10 \%(3.0 \pm 1.4 \mathrm{msec})$ of control $\mathrm{IPSG}_{50}(n=6)$. OA decreased IPSG $_{50}$ by $36 \pm 12 \%(3.6 \pm 1.1 \mathrm{msec})$ of control value $(n=7)$. Finally, as in our analysis of F2 facilitation (Vyshedskiy and Lin, 1997c), we were not able to demonstrate conclusively a change in minimal synaptic delay during 5-HT and OA-mediated synaptic enhancement.

The area of IPSG (IPSG ${ }_{\text {area }}$ ) reflects the transmitter content of the early component of continuous transmitter release (Vyshedskiy and Lin, 1997c). The early component was defined as an initial transient component of transmitter release, with a duration of $\sim 15 \mathrm{msec}$, which is followed by a steady-state, or late, component that persists for several seconds. Both 5-HT and OA increased IPSG area $_{\text {. The time course of the change in IPSG }}$ after each of the modulators was applied is illustrated in Figure 4, $D_{1}$ and $D_{2}$. On average, 5 -HT increased IPSG $_{\text {area }}$ by $50 \pm 21 \%$ $(n=6)$ and OA increased IPSG area $_{1}$ by $\pm 6 \%(n=7)$. This observation markedly differs from the activity-induced F2 facilitation, which does not change IPSG $_{\text {area }}$ (Vyshedskiy and Lin, 1997c) (also see below). [There was an apparent difference in the time course of IPSG $_{50}$ (Fig. $4 C_{1}$ ) and IPSG $_{\text {area }}$ (Fig. $4 D_{1}$ ) after 

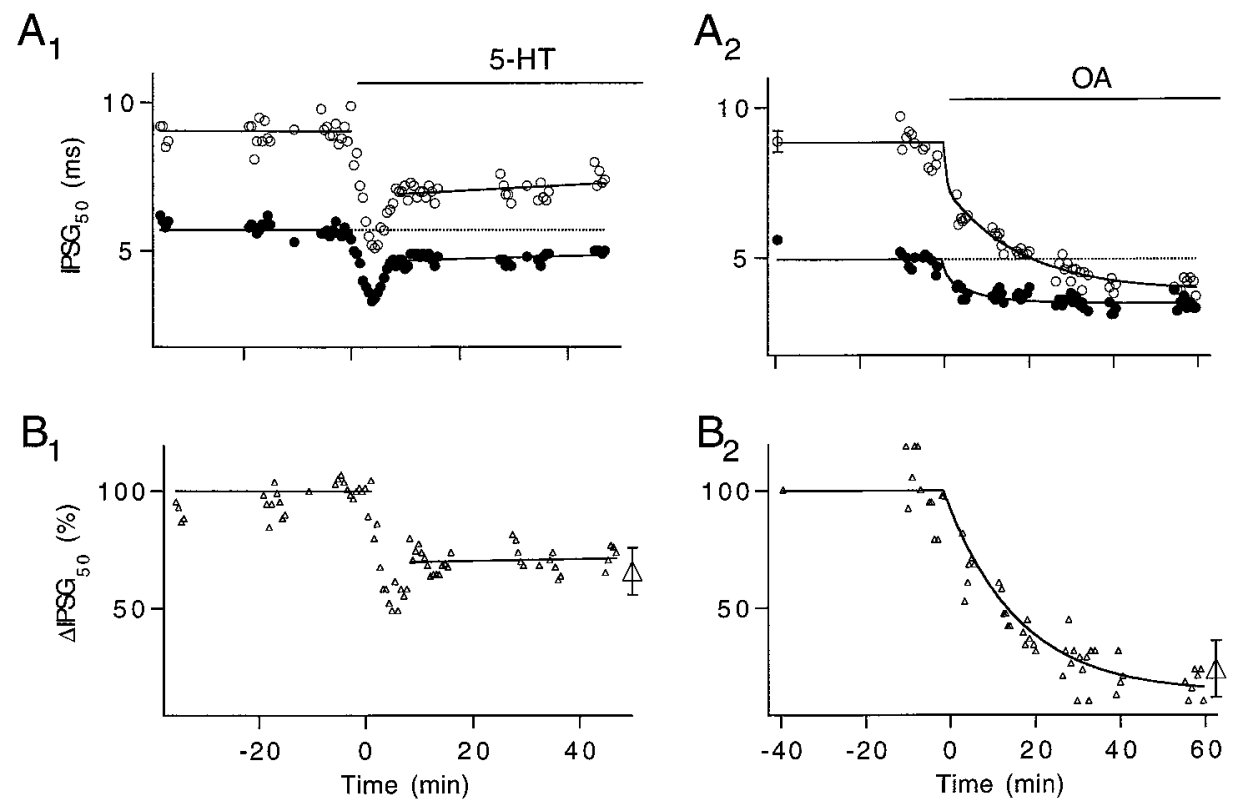

Figure 5. Interaction between synaptic enhancement mediated by $\mathrm{F} 2$ facilitation and modulators. $A$, IPSG $_{50}$ measured from both control $(\bigcirc)$ and facilitated $(\bullet)$ IPSGs is decreased by $100 \mathrm{nM} 5$-HT $\left(A_{1}\right)$ and $2.5 \mu \mathrm{M}$ OA $\left(A_{2}\right)$. The dotted lines are used to highlight the fact that 5-HT did not decrease IPSG ${ }_{50}$ beyond the level achieved by F2 facilitation, whereas $\mathrm{OA}$ was able to reduce IPSG $_{50}$ beyond that level. $B$, The effect of $\mathrm{F} 2$ facilitation is quantified by calculating the difference between control and facilitated $\mathrm{IPSG}_{50}\left(\Delta \mathrm{IPSG}_{50}\right)$. Both 5-HT $\left(B_{1}\right)$ and OA $\left(B_{2}\right)$ decrease $\Delta \mathrm{IPSG}_{50}$. The averaged percentage change in $\triangle \mathrm{IPSG}_{50}$ is shown also, with SD (see Results). Membrane characteristics of the muscle fiber used in the 5-HT experiment were $10.4 \mathrm{mV}, 0.89$ $\mathrm{M} \Omega, 13.5 \mathrm{msec}$ and $10.4 \mathrm{mV}, 0.88 \mathrm{M} \Omega, 13.3$ msec. The same parameters measured from the OA experiment were $6.6 \mathrm{mV}, 0.38 \mathrm{M} \Omega, 9.0$ $\mathrm{msec}$ and $6.8 \mathrm{mV}, 0.39 \mathrm{M} \Omega, 9.3 \mathrm{msec}$.

5-HT application. This difference was attributable mainly to changes in bath temperature associated with rapid solution exchange. Control experiments in which 5-HT was introduced slowly, and without disturbing bath temperature, revealed a similar time course for IPSG $_{50}$ and IPSG

\section{Interaction between F2 facilitation and modulator- mediated synaptic enhancement}

To investigate whether the accelerated release kinetics could be a mechanism shared by modulator-mediated synaptic enhancement and activity-dependent plasticity, we investigated the interaction between these two types of synaptic enhancement. The magnitude of F2 facilitation was compared before and after the modulators were introduced. F2 facilitation was activated by a burst of eight subthreshold conditioning pulses, a conditioning stimulus known to activate a near-maximal level of facilitation without triggering significant transmitter release (Vyshedskiy and Lin, 1997b). The magnitude of F2 facilitation, measured $150 \mathrm{msec}$ after the conditioning stimulus, was quantitated by measuring the difference between control and facilitated $\mathrm{IPSG}_{50}\left(\Delta \mathrm{IPSG}_{50}\right.$ or release shift). This difference has been shown to be related linearly to the magnitude of F2 facilitation estimated from IPSG amplitudes (Vyshedskiy and Lin, 1997c). (To avoid conf usion, we have referred to the increase in synaptic strength associated with F2 facilitation as facilitation, whereas we have referred to the increase mediated by the modulators as enhancement.)

Figure 5, $A_{1}$ and $A_{2}$, illustrates the effects of 5-HT and OA on control $(\bigcirc)$ and facilitated $(\bigcirc) \mathrm{IPSG}_{50}$. As in the example shown in Figure 4, 5-HT and OA decreased control $\mathrm{IPSG}_{50}$. IPSG measured from facilitated responses also was reduced by 5-HT and $\mathrm{OA} . \triangle \mathrm{IPSG}_{50}$, which reflects the magnitude of $\mathrm{F} 2$ facilitation, was reduced significantly by the modulators (Fig. $5 B_{1}, B_{2}$ ). On average, 5 -HT decreased the release shift by $39 \pm 10 \%(1.5 \pm$ $0.5 \mathrm{msec}, n=6$ ), whereas OA decreased the release shift by $76 \pm$ $12 \%(2.4 \pm 0.8 \mathrm{msec}, n=7)$. The observation that the release shift was reduced in the presence of modulators suggests that F2 facilitation and the modulators may share a common pathway that leads to accelerated release kinetics.

It has been shown that $\mathrm{F} 2$ facilitation does not affect $\mathrm{IPSG}_{\text {area }}$ (Vyshedskiy and Lin, 1997c). This observation remains true in the presence of 5-HT and OA. The normalized change in IPSG $_{\text {area }}$ is defined as:

$$
\Delta \mathrm{IPSG}_{\text {area }}=\left[\left(\mathrm{IPSG}_{\text {test(area) }} / \mathrm{IPSG}_{\mathrm{cnt}(\text { (area })}\right)-1\right] \cdot 100 \%,
$$

where IPSG cnt(area) $_{\text {and IPSG }}$ test(area) represent control and facilitated $\mathrm{IPSG}_{\text {area }}$, respectively. $\triangle \mathrm{IPSG}_{\text {area }}$ was $1.3 \pm 5.5 \%(n=$ $13)$ in control saline and was $-2.0 \pm 5.4 \%(n=6)$ and $4.1 \pm 5.2 \%$ $(n=7)$ in 5 -HT and OA, respectively. None of these values is statistically different from zero. Therefore, the presence of modulators does not change one of the main characteristics of F2 facilitation, i.e., IPSG area remains constant.

\section{DISCUSSION}

We have demonstrated that 5-HT and OA enhance transmitter output by presynaptic mechanisms that do not involve an increase in the level of resting or action potential-activated $\left[\mathrm{Ca}^{2+}\right]_{\mathrm{i}}$. These modulators enhance transmitter output by accelerating release kinetics and by increasing the total amount of transmitter release. Together with the finding that the release kinetics can be modulated without changing the amount of total release by F2 facilitation, the results reported here provide strong support for the hypothesis that there exist at least two separate mechanisms for enhanced transmitter release that are independent of calcium influx or resting $\left[\mathrm{Ca}^{2+}\right]_{\mathrm{i}}$. Furthermore, the presynaptic voltage control method allows us to monitor directly the two mechanisms physiologically.

Additional support for the above-mentioned hypothesis can be derived from the results of the interaction between the two modulators and F2 facilitation. Plots in Figure $5 A$ show that, during the steady state, 5-HT was not able to decrease IPSG $_{50}$ to the level mediated by $\mathrm{F} 2$ facilitation, whereas OA decreased IPSG $_{50}$ beyond that level (dotted lines in Fig. $5 A_{1}, A_{2}$ ). This was a consistent observation, $n=6$ for 5 -HT and $n=6$ for OA. Although one could attribute this difference to the relatively low concentration of 5-HT used in this report, concurrent comparison of the effects of the two modulators on IPSG $_{\text {area }}$ suggests that this interpretation is too simplistic. Specifically, despite the effectiveness of $\mathrm{OA}$ in accelerating release kinetics, its ability to increase IPSG $_{\text {area }}$ is lower than that of 5-HT (see Fig. 4D). Therefore, OA 


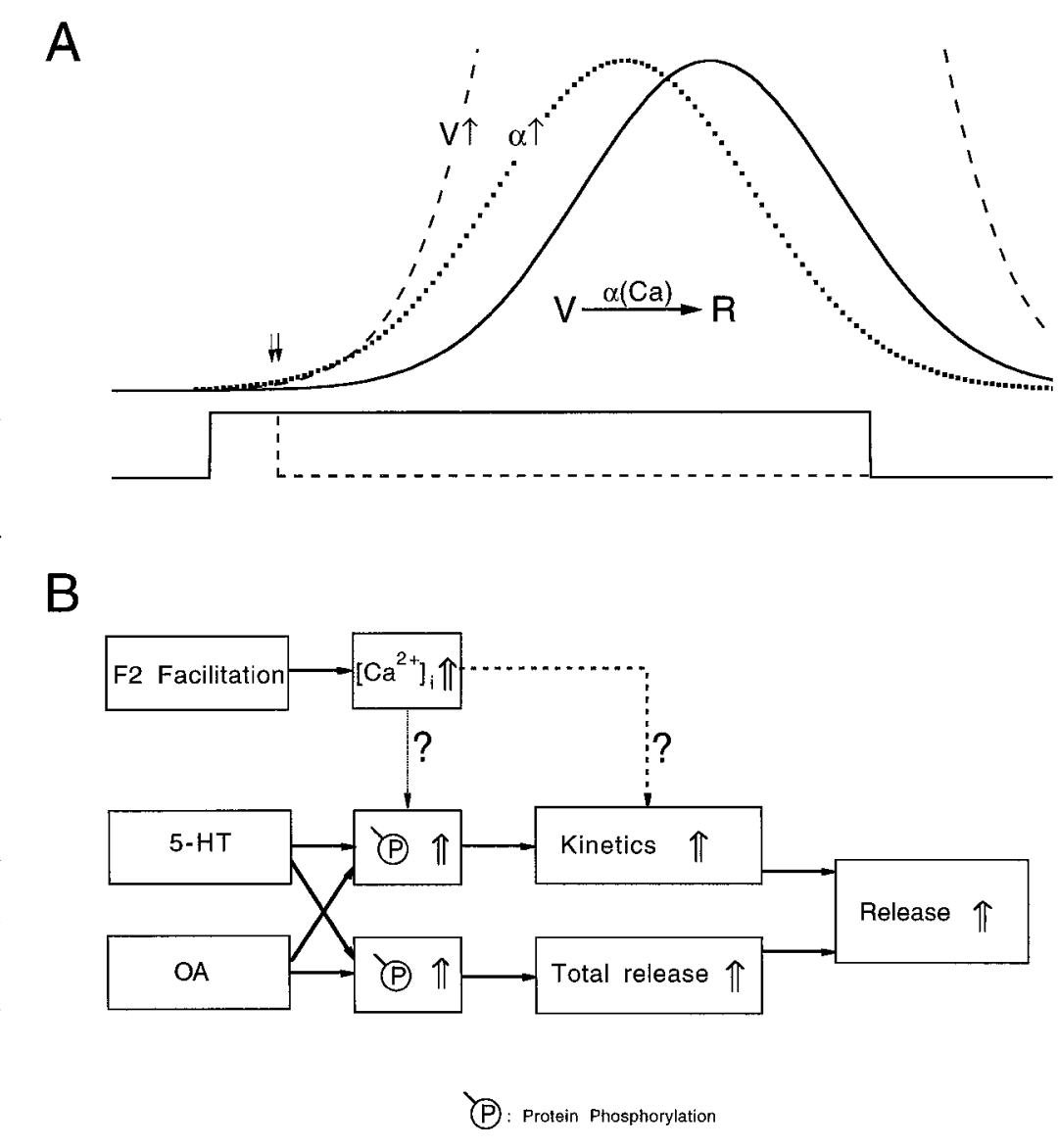

Figure 6. Multiple mechanisms for enhancement transmitter release. $A$, A schematic drawing to illustrate the two mechanisms that can enhance transmitter release. The solid curve in the upper panel represents the time course of vesicular release activated by a $20 \mathrm{msec}$ presynaptic pulse (lower trace, solid line). Transmitter release can be increased by accelerating release kinetics (wide-spaced dotted line and $\alpha \uparrow$ ) and/or by increasing the total number of vesicles released without altering release kinetics (dashed line and $\mathrm{V} \uparrow$ ). A brief presynaptic depolarization with a duration of $2.5 \mathrm{msec}$ (lower trace, dashed line) allows one to observe only the beginning of transmitter release and therefore does not provide sufficient resolution to observe the mechanisms underlying release (double arrows). Inset, The transmitter release process is modeled according to a simple reaction in which $V$ represents the concentration of available vesicles and $R$ represents release; the secretion step has a forward reaction rate of $\alpha$, which is modulated by calcium ions. $B$, Block diagram illustrating different mechanisms that could increase transmitter output and the relationship between activity-dependent and modulator-mediated synaptic enhancement. 5-HT and OA are both able to increase protein phosphorylation. Physiological effects of protein phosphorylation include an acceleration in release kinetics and an increase in total release. Both mechanisms result in an increase in action potential-activated release. Facilitation processes have access only to the kinetic branch of the flow chart. It remains unclear whether the increase in $\left[\mathrm{Ca}^{+2}\right]_{\mathrm{i}}$ associated with $\mathrm{F} 2$ facilitation accelerates release kinetics by way of protein phosphorylation (dotted arrow) or processes further downstream (dashed arrow). is more effective in accelerating kinetics than 5-HT, whereas the ability of OA to increase IPSG area is weaker than that of 5-HT at $100 \mathrm{~nm}$. This observation provides further support for the hypothesis that transmitter release kinetics and total release represent two separate mechanisms that can be modulated separately or differentially.

Because the modulators and F2 facilitation appear to share a common mechanism underlying the accelerated release kinetics, one would expect the magnitude of F2 facilitation to be reduced in 5-HT and OA. This prediction is consistent with the finding that $5 \mu \mathrm{M}$ OA effectively reduces facilitation (Swain et al., 1991). It has been shown that 5-HT reduces the magnitude of facilitation at $25 \mu \mathrm{M}$ but has no effect at $25 \mathrm{~nm}$ (Fischer and Florey, 1983). Our results suggest a clear interaction between $100 \mathrm{~nm}$ 5-HT and F2 facilitation. Our results and those of Fischer and Florey (1983) are consistent if one assumes that release kinetics is modulated by 5-HT in a concentration-dependent manner.

Despite rigorous pursuit it had not been possible previously to demonstrate changes in release kinetics, during facilitation, with transmitter release activated by action potentials or brief presynaptic depolarization (Datyner and Gage, 1980; Parnas et al., 1989). The presynaptic voltage control method is able to provide a clear demonstration of changes in release kinetics. The success of this method can be explained by comparing action potentialbased studies and studies using the presynaptic control method (Fig. 6A). The increase in transmitter release could be attributable to an increase in the total amount of transmitter content (dashed line and $\mathrm{V} \uparrow$ ) and/or attributable to an acceleration in release kinetics without changing transmitter content (widespaced dotted line and $\alpha \uparrow$ ). The differentiation between the two mechanisms is obvious when the duration of presynaptic depolarization is $20 \mathrm{msec}$ (Fig. 6A, lower trace, solid line). In contrast, an action potential with a duration of $2.5 \mathrm{msec}$ only allows for a narrow window of observation (Fig. 6A, lower trace, dashed line and double arrows). With such a short period of observation, the only significant change in the postsynaptic response is in its amplitude. Kinetic changes would be difficult to resolve unless there was a clear shift in synaptic delay. Therefore, prolonged presynaptic depolarization provides a simple way to visualize directly certain mechanisms underlying the increase in transmitter output.

\section{Mechanisms of 5-HT and OA effects}

Second messenger pathways involved in 5-HT-mediated synaptic enhancement have been studied in detail at the crayfish excitor. A brief application of 5-HT evoked two distinct components of synaptic enhancement, a transient and a persistent component (Dixon and Atwood, 1985). It was suggested that the early and transient component is mediated by the $\mathrm{IP}_{3} /$ protein kinase $\mathrm{C}$ pathway, whereas the late and persistent component is mediated by the protein kinase A pathway (Dixon and Atwood, 1989b,c). Assuming that the actions of 5-HT on the inhibitor are identical to those on the excitor, it is reasonable to suggest that both the release kinetics and total release can be modulated by protein phosphorylation. As a result, the qualitative similarities between the effects of 5-HT and OA are not surprising, because OA also can enhance protein phosphorylation by retarding the dephosphorylation process (Bialojan and Takai, 1988; Cohen et al., 1990). A summary of the effects of these two modulators is illustrated in the form of a block diagram in Figure $6 B$. Possible 
targets of the phosphorylation process under our experimental conditions remain undefined. Effects of protein phosphorylation on the transmitter secretion process also have been implicated in the sensory-motor synapses of Aplysia (Hochner et al., 1986a; Byrne and Kandel, 1996), the squid giant synapse (Lin et al., 1990; Llinás et al., 1991), and transgenic mice (Rosahl et al., 1995).

\section{Acceleration in release kinetics}

Kinetic description of the transmitter secretion process traditionally has been modeled as a chemical reaction in which free calcium ions act as a catalyst (Fig. 6A, inset). To increase transmitter release $(R)$, one could (1) increase $\left[\mathrm{Ca}^{2+}\right]_{\mathrm{i}},(2)$ increase the concentration of available vesicles $(V)$, or $(3)$ increase the forward reaction rate $(\alpha)$. Our results suggest that 5-HT and OA do not increase $\left[\mathrm{Ca}^{2+}\right]_{\mathrm{i}}$. The two physiological parameters analyzed here, release kinetics and total release, are conceptually equivalent to the forward reaction rate and the concentration of available vesicles, respectively.

It would be too simplistic to take the acceleration in release kinetics literally and to try to construct a quantitative model by increasing the forward reaction rate. Here, we discuss the accelerated release conceptually in the context of two observations. First, there is no detectable change in minimal synaptic delay during F2 facilitation (Vyshedskiy and Lin, 1997c) or modulatormediated synaptic enhancement. Second, there is a decrease in apparent calcium cooperativity during F2 facilitation (Stanley, 1986; Vyshedskiy and Lin, 1997b). We propose that the accelerated release is attributable to a redistribution in the states of synaptic vesicles. Specifically, available vesicles are assumed to be in various states of readiness for release. Highly ready vesicles will be released first and less ready vesicles will be released later (Fig. $6 A$, upper trace, solid line), if calcium influx continues during a 20 msec presynaptic depolarization (Fig. 6A, lower trace, solid line). Both the facilitation process and modulators increase the fraction of vesicles that are in a highly ready state. If the minimal synaptic delay is determined by the presence of vesicles in the highly ready state, an increase in the fraction of these vesicles should not change the detection of the minimal delay.

The precise definition of the vesicular states remains a matter of speculation. For example, different vesicular states may correspond to various stages of assembly of the docking complex that includes, but is not limited to, synaptobrevin, syntaxin, SNAP-25, synaptotagmin, and calcium channels (for review, see Sollner and Rothman, 1996). Alternatively, different vesicular states may correspond to various levels of phosphorylation of the docking complex proteins (Fujita et al., 1996; Hirling and Scheller, 1996; Shimazaki et al., 1996; Yokoyama et al., 1997). The physiological significance of these biochemically defined states is not completely understood. An alternative definition of various states of readiness could be made at a physiological level. Specifically, they may reflect the state of calcium binding sites associated with the secretion machinery. It has been proposed that facilitation is attributable to the filling of high-affinity calcium binding sites of the secretion machinery (Stanley, 1986; Yamada and Zucker, 1992; Winslow et al., 1994; Bertram et al., 1996). This definition theoretically could generate a detectable change in release kinetics during prolonged release and represents a direct modulation of elevated $\left[\mathrm{Ca}^{2+}\right]_{\mathrm{i}}$ on vesicular states (Fig. $6 \mathrm{~B}$, dashed arrow). In addition, this model fits well with the finding that calcium cooperativity is decreased during facilitation. Therefore, known ki- netic properties of F2 facilitation are well accounted for by this model.

However, this line of logic cannot explain the finding that the modulators and F2 facilitation share the same pathway leading to an acceleration in release kinetics. How can 5-HT and OA accelerate release kinetics by filling the high-affinity calcium binding sites when neither of the modulators increases $\left[\mathrm{Ca}^{2+}\right]_{\mathrm{i}}$ ? One way to resolve this controversy would be to assume that protein phosphorylation may "activate" one of the calcium binding sites such that the calcium binding of that site would not be necessary for secretion. (Alternatively, the affinity of the calcium binding sites could be increased by phosphorylation such that some of the sites would be occupied at the resting level of $\left[\mathrm{Ca}^{2+}\right]_{\mathrm{i}}$.) Supporting evidence for this hypothesis comes from the Drosophila dnc mutant in which the cellular cAMP-dependent phosphorylation level is elevated (Byers et al., 1981). The calcium cooperativity of transmitter release in this mutant is 3 , rather than 4 as observed in wild-type animals, which suggests the possibility that protein phosphorylation could modulate calcium cooperativity (Zhong and $\mathrm{Wu}, 1991)$. However, there is also evidence indicating no change in calcium cooperativity in 5-HT (Glusman and Kravitz, 1982). The second way to resolve this controversy would be to propose that $\mathrm{F} 2$ facilitation also passes through protein phosphorylation (Fig. 6B, dotted arrow). Because it is well documented that elevated intracellular free calcium is the main driving element for synaptic facilitation, it is conceivable that calcium/calmodulindependent protein kinase pathways could underlie synaptic facilitation. Pharmacological studies, however, have failed to substantiate a role for the CAM kinase II pathway in F2 facilitation in the inhibitor. [We have tested calmidasolium (up to $50 \mu \mathrm{M}$ ), $n=2$; $\mathrm{KN}-62$ (up to $100 \mu \mathrm{M}$ ), $n=3$; KN-93 (up to $50 \mu \mathrm{M}$ ), $n=2$; and $\mathrm{K}-252 \mathrm{a}$ (up to $5 \mu \mathrm{M}$ ), $n=2$. None of the drugs significantly altered F2 facilitation. See also Kamiya and Zucker (1994) for experiments in the excitor.] Therefore, further study is needed to understand molecular mechanisms for the modulator-mediated acceleration in release kinetics.

\section{Regulation of total release}

Results reported here demonstrate that 5-HT and OA are able to increase the total amount of transmitter release mediated by a 20 msec pulse. A $20 \mathrm{msec}$ step depolarized to $0 \mathrm{mV}$ releases up to $90 \%$ of the transmitter content of an early component of continuous transmitter release (Vyshedskiy and Lin, 1997c). The specific mechanism that underlies this early component is unknown. An obvious possibility is that this component reflects a pool of available vesicles, which includes vesicles in various states of readiness. The modulation of the size of this pool by 5-HT and OA then could be considered in terms of vesicular mobilization resulting in a larger number of available vesicles. Because of our limited understanding in the dynamics of vesicular mobilization during continuous transmitter release, it is difficult to discuss the concept of available vesicles in more specific terms.

Factors other than a vesicular pool with vesicles in various states of readiness also can shape the transmitter release time course and create an "apparent" available pool. For example, inactivation of calcium current (Wright et al., 1996a,b), adaptation of the release process (Hsu et al., 1996), calcium sequestration during the $20 \mathrm{msec}$ pulse (Herrington et al., 1996), or a combination of GABA receptor desensitization and increased GABA reuptake during the $20 \mathrm{msec}$ pulse may all create a transient component during continuous release. Because 5-HT and $\mathrm{OA}$ increase neither the resting nor the action potential- 
activated $\left[\mathrm{Ca}^{2+}\right]_{\mathrm{i}}$, a decrease in calcium current inactivation or a decrease in calcium sequestration, during $20 \mathrm{msec}$ pulses, can be ruled out as possible pathways by which the modulators could increase total release. In addition, because responses evoked by iontophoretically applied GABA were not changed by the modulators, the possibility that postsynaptic modulation creates an apparent increase in total release can be ruled out also. The adaptation process has been described in the squid giant synapse where transmitter secretion is prematurely terminated, in the presence of high $\left[\mathrm{Ca}^{2+}\right]_{\mathrm{i}}$, and in the absence of vesicle depletion. This process has not been studied in the crayfish neuromuscular junctions and cannot be ruled out as a possible target for the modulation of total release. Consequently, 5-HT and OA may increase total release by slowing or blocking the adaptation process or by increasing the number of available vesicles in the early component.

In conclusion, this report demonstrates the presence of at least two separate mechanisms for the enhancement of transmitter release. The separation of these mechanisms by distinct physiological parameters should facilitate future studies of the molecular basis for these mechanisms.

\section{REFERENCES}

Atwood HL, Dixon D, Wojtowicz JM (1989) Rapid introduction of long-term synaptic changes at crustacean neuromuscular junction. J Neurobiol 20:373-385.

Bertram R, Sherman A, Stanley EF (1996) Single-domain/bound calcium hypothesis of transmitter release and facilitation. J Neurophysiol 75:1919-1931.

Bialojan C, Takai A (1988) Inhibitory effect of a marine-sponge toxin, okadaic acid, on protein phosphorylation. Biochem J 256:283-290.

Bittner GD (1989) Synaptic plasticity at the crayfish opener neuromuscular preparation. J Neurobiol 20:386-406.

Byers D, Davis RL, Kiger JA (1981) Defect in cyclic AMP phosphodiesterase due to the dunce mutation of learning in Drosophila melanogaster. Nature 289:79-81.

Byrne JH, Kandel ER (1996) Presynaptic facilitation revisited: state and time dependence. J Neurosci 16:425-435.

Cohen P, Holmes CFB, Tsukitani Y (1990) Okadaic acid: a new probe for the study of cellular regulation. Trends Biochem 15:98-102.

Dale N, Kandel ER (1990) Facilitatory and inhibitory transmitters modulate spontaneous transmitter release at cultured Aplysia sensorimotor synapses. J Physiol (Lond) 427:203-222.

Datyner NB, Gage PW (1980) Phasic secretion of acetylcholine at a mammalian neuromuscular junction. J Physiol (Lond) 303:299-314.

Delaney KR, Zucker RS, Tank DW (1989) Calcium in motor nerve terminals associated with post-tetanic potentiation. J Neurosci 9:3558-3567.

Delaney KR, Tank DW, Zucker RS (1991) Presynaptic calcium and serotonin-mediated enhancement of transmitter release at crayfish neuromuscular junction. J Neurosci 11:2631-2643.

Dittman JS, Regehr WG (1996) Contribution of calcium-dependent and calcium-independent mechanisms to presynaptic inhibition at a cerebellar synapse. J Neurosci 16:1623-1633.

Dixon D, Atwood HL (1985) Crayfish motor nerve terminal's response to serotonin examined by intracellular microelectrode. J Neurobiol 16:409-424.

Dixon D, Atwood HL (1989a) Adenylate cyclase system is essential for long-term facilitation at the crayfish neuromuscular junction. J Neurosci 9:4246-4252.

Dixon D, Atwood HL (1989b) Conjoint action of phosphatidylinositol and adenylate cyclase systems in serotonin-induced facilitation at the crayfish neuromuscular junction. J Neurophysiol 62:1251-1259.

Dixon D, Atwood HL (1989c) Phosphatidylinositol system's role in serotonin-induced facilitation at the crayfish neuromuscular junction. J Neurophysiol 62:239-246.

Fischer L, Florey E (1983) Modulation of synaptic transmission and excitation-contraction coupling in the opener muscle of the crayfish, Astacus leptodactylus, by 5-hydroxytryptamine and octopamine. J Exp Biol 102:187-198.
Fujita Y, Sasaki T, Fukui K, Kotani H, Kimura T, Hata Y, Sudhof TC, Scheller RH, Takai Y (1996) Phosphorylation of Munc-18/n-Sec1/rbSec1 by protein kinase $\mathrm{C}$ : its implication in regulating the interaction of Munc-18/n-Sec1/rb-Sec1 with syntaxin. J Biol Chem 271:7265-7268.

Glusman S, Kravitz EA (1982) The action of serotonin on excitatory nerve terminals in lobster nerve-muscle preparations. J Physiol (Lond) 325:223-241.

Herrington J, Park YB, Babcock DF, Hille B (1996) Dominant role of mitochondria in clearance of large $\mathrm{Ca}^{2+}$ loads from rat adrenal chromaffin cells. Neuron 16:219-228.

Hessler NA, Shirke AM, Malinow R (1993) The probability of transmitter release at a mammalian central synapse. Nature 366:569-572.

Hirling H, Scheller RH (1996) Phosphorylation of synaptic vesicle proteins: modulation of the $\alpha$ SNAP interaction with the core complex. Proc Natl Acad Sci USA 93:11945-11949.

Hochner B, Klein M, Schacher S, Kandel ER (1986a) Action potential duration and the modulation of transmitter release from the sensory neurons of Aplysia in presynaptic facilitation and behavioral sensitization. Proc Natl Acad Sci USA 83:8410-8414.

Hochner B, Klein M, Schacher S, Kandel ER (1986b) Additional component in the cellular mechanism of presynaptic facilitation contributes to behavioral disinhibition. Proc Natl Acad Sci USA 83:8794-8798.

Hsu S-F, Augustine GJ, Jackson MB (1996) Adaptation of $\mathrm{Ca}^{2+}$. triggered exocytosis in presynaptic terminals. Neuron 17:501-512.

Huang C-C, Hsu KS, Gean PW (1996) Isoproterenol potentiates synaptic transmission primarily by enhancing presynaptic calcium influx via $\mathrm{P}$ - and/or Q-type calcium channels in the rat amygdala. J Neurosci 16:1023-1033.

Kamiya H, Zucker RS (1994) Residual $\mathrm{Ca}^{2+}$ and short-term synaptic plasticity. Nature 371:603-606.

Klein M (1994) Synaptic augmentation by 5-HT at rested Aplysia sensorimotor synapses: independence of action potential prolongation. Neuron 13:159-166.

Lin J-W, Sugimori M, Llinás RR, McGuinness TL, Greengard P (1990) Effects of synapsin I and calcium/calmodulin-dependent protein kinase II on spontaneous neurotransmitter release in the squid giant synapse. Proc Natl Acad Sci USA 87:8257-8261.

Llinás R, Gruner JA, Sugimori M, McGuinness TL, Greengard P (1991) Regulation by synapsin I and $\mathrm{Ca}^{2+}$-calmodulin-dependent protein kinase II of the transmitter release in squid giant synapse. J Physiol (Lond) 436:257-282.

Magleby KL (1987) Short-term changes in synaptic efficacy. In: Synaptic function (Edelman G, Gall WE, Cowan WM, eds), pp 21-56. New York: Wiley.

Malgaroli A, Tsien RW (1992) Glutamate-induced long-term potentiation of the frequency of miniature synaptic currents in cultured hippocampal neurons. Nature 357:134-139.

Man-Son-Hing H, Zoran MJ, Lukowiak K, Haydon PG (1989) A neuromodulator of synaptic transmission acts on the secretory apparatus as well as on ion channels. Nature 341:237-239.

McGehee DD, Heath MJ, Gelber S, Devay P, Role LW (1995) Nicotine enhancement of fast excitatory synaptic transmission in the CNS by presynaptic receptors. Science 269:1692-1696.

Mclachlan EM (1978) The statistics of transmitter release at chemical synapses. Int Rev Physiol 17:49-117.

Parnas H, Hovav G, Parnas I (1989) Effect of $\mathrm{Ca}^{2+}$ diffusion on the time course of neurotransmitter release. Biophys J 55:859-874.

Rosahl TW, Spillane D, Missler M, Herz J, Selig DK, Wolff JR, Hammer RE, Malenka RC, Sudhof TC (1995) Essential functions of synapsins I and II in synaptic vesicle regulation. Nature 375:488-493.

Rosenmund C, Clements JD, Westbrook GL (1993) Nonuniform probability of glutamate release at a hippocampal synapse. Science 262:754-757.

Scanziani M, Capogna M, Gahwiler BH, Thompson SM (1992) Presynaptic inhibition of miniature excitatory synaptic currents by baclofen and adenosine in the hippocampus. Neuron 9:919-927.

Scholz KP, Miller RJ (1992) Inhibition of quantal transmitter release in the absence of calcium influx by a G-protein-linked adenosine receptor at hippocampal synapses. Neuron 8:1139-1150.

Shimazaki Y, Nishiki T, Omori A, Sekiguchi M, Kamata Y, Kozaki S, Takahashi M (1996) Phosphorylation of $25 \mathrm{kDa}$ synaptosomeassociated protein. J Biol Chem 271:14548-14553.

Sollner TH, Rothman JE (1996) Molecular machinery mediating vesicle budding, docking, and fusion. Experientia 52:1021-1025. 
Stanley EF (1986) Decline in calcium cooperativity as the basis of facilitation at the squid giant synapse. J Neurosci 6:782-789.

Swain JE, Robitaille R, Dass GR, Charlton MP (1991) Phosphatases modulate transmission and serotonin facilitation at synapses: studies with the inhibitor okadaic acid. J Neurobiol 22:855-864.

Takeuchi A, Takeuchi N (1965) Localized action of gamma-amino butyric acid on the crayfish muscle. J Physiol (Lond) 177:225-238.

Tank DW, Regehr WG, Delaney KR (1995) A quantitative analysis of presynaptic calcium dynamics that contribute to short-term enhancement. J Neurosci 15:3539-3547.

Trudeau L-E, Emery DG, Haydon PG (1996) Direct modulation of the secretory machinery underlies PKA-dependent synaptic facilitation in hippocampal neurons. Neuron 17:789-797.

Vyshedskiy A, Lin J-W (1997a) A study of the inhibitor of the crayfish neuromuscular junction by presynaptic voltage control. J Neurophysiol 77:103-115.

Vyshedskiy A, Lin J-W (1997b) Activation and detection of facilitation as studied by presynaptic voltage control at the inhibitor of the crayfish opener muscle. J Neurophysiol 77:2300-2315.

Vyshedskiy A, Lin J-W (1997c) Change of transmitter release kinetics during facilitation revealed by prolonged test pulses at the inhibitor of the crayfish opener muscle. J Neurophysiol 78:1791-1799.

Winslow JL, Duffy SN, Charlton MP (1994) Homosynaptic facilitation of transmitter release in crayfish is not affected by mobile calcium chelators: implications for the residual ionized calcium hypothesis from electrophysiological and computational analysis. J Neurophysiol 72:1769-1793.

Wright SN, Brodwick MS, Bittner GD (1996a) Calcium currents, transmitter release, and facilitation of release at voltage-clamped crayfish nerve terminals. J Physiol (Lond) 496:363-378.

Wright SN, Brodwick MS, Bittner GD (1996b) Presynaptic calcium currents at voltage-clamped excitor and inhibitor nerve terminals of crayfish. J Physiol (Lond) 496:347-361.

Yamada MW, Zucker RS (1992) Time course of transmitter release calculated from stimulations of a calcium diffusion model. Biophys $\mathrm{J}$ 61:671-682.

Yokoyama CT, Sheng Z-H, Catterall WA (1997) Phosphorylation of the synaptic protein interaction site on $\mathrm{N}$-type calcium channels inhibits interactions with SNARE proteins. J Neurosci 17:6929-6938.

Zhong Y, Wu C-F (1991) Altered synaptic plasticity in Drosophila memory mutants with a defective cyclic AMP cascade. Science 251:198-201.

Zucker RS (1973) Changes in the statistics of transmitter release during facilitation. J Physiol (Lond) 229:787-810.

Zucker RS (1996) Exocytosis: a molecular and physiological perspective. Neuron 17:1049-1055. 